\title{
Classicismo Moderno. Margherita SARFatti e o Novecento Italiano, entre Brasil e Estados Unidos
}

\begin{abstract}
Ana Magalhães* 1
RESUMO: O presente artigo tem por objetivo analisar a presença da crítica de arte italiana, Margherita Sarfatti (1880-1961), na América do Sul, e seu papel na formação do núcleo inicial do acervo do Museu de Arte Moderna de São Paulo (MAM) - atualmente pertencente ao acervo do Museu de Arte Contemporânea da Universidade de São Paulo (MAC USP). Fundadora do chamado Novecento Italiano, em plena era fascista, na Itália, Sarfatti teve um papel relevante na promoção da arte moderna italiana no continente americano, fazendo viagens ao Brasil, à Argentina e, mais tarde, aos Estados Unidos. Pretendemos, portanto, analisar comparativamente como Sarfatti e sua noção de arte moderna italiana foram vistas pelo Brasil e pelos Estados Unidos, antes e depois da II Guerra Mundial, para assim entender a formação do primeiro acervo de arte moderna da América do Sul dentro do programa maior da diplomacia italiana, antes e depois da queda do Fascismo.

PALAVRAS-CHAVE: Margherita Sarfatti, Arte moderna italiana, Novecento Italiano, Museu de Arte Moderna de São Paulo, colecionismo, diplomacia cultural
\end{abstract}

ABSTRACT: This essay aims at analyzing the presence of Italian art critic, Margherita Sarfatti, in South America, and her role in the making of the collection of the São Paulo Museum of Modern Art (MAM) - nowadays belonging into the collections of the Museum of Contemporary Art of the University of São Paulo (MAC USP). Founder of the so-called Novecento Italiano, in the fascist era in Italy, Sarfatti was very active in the promotion of Italian modern art in the American continent, during trips that she took, respectively, to Brazil, Argentina, and later to the United States. We thus intend to analyze how Sarfatti and her notion of Italian modern art were received in Brazil and in the United States, before and after the II World War, so as to understand the making of the first public collection of modern art in South America in the larger framework of Italian diplomacy, before and after the fall of fascism.

KEYWORDS: Margherita Sarfatti, Italian modern art, Novecento Italiano, São Paulo Museum of Modern Art, collecting, cultural diplomacy

"MAC - USP (Universidade de São Paulo) — amagalhaes@usp.br

DOI: http://dx.doi.org/10.11606/issn.2238-8281.v0i37p37-57

1 Agradeço à minha ex-orientanda Marina Barzon Silva pela tradução do texto ao português, cuja primeira versão, apresentada em conferência na Universidade da Flórida, em setembro de 2017, permanece inédita. Também gostaria de esclarecer que a seleção de imagens para acompanhar o artigo privilegia o material levantado por Marina Barzon Silva nos jornais brasileiros, quando estagiou comigo no MAC USP. 
ABSTRACT: Quest'articolo ha per tema centrale la presenza del critico d'arte italiana Margherita Sarfatti (1880-1961) in Sudamerica, e il suo ruolo nella formazione del nucleo iniziale della raccolta del Museu de Arte Moderna di Sao Paulo (MAM) - oggi appartenente alla raccolta del Museu de Arte Contemporânea da Universidade de São Paulo (MAC USP). Creatrice del cosiddetto Novecento Italiano, in piena epoca fascista in Italia, Sarfatti ha avuto un ruolo di spicco nella promozione dell'arte moderna italiana nel continente americano, realizzando viaggi in Brasile, in Argentina e, più avanti, negli Stati Uniti. Si intende qui analizzare comparativamente come Sarfatti e la sua nozione di arte moderna italiana sono stati ricevuti in Brasile e negli Stati Uniti, prima e dopo la Seconda Grande Guerra, per capire così come è avvenuta la formazione della prima raccolta di arte moderna del Sudamerica all'interno del programma più ampio della diplomazia italiana, prima e dopo la caduta del Fascismo.

PAROLE CHIAVE: Margherita Sarfatti, Arte moderna italiana, Novecento italiano, Museo d'Arte moderna di Sao Paulo, collezionismo, diplomazia culturale 


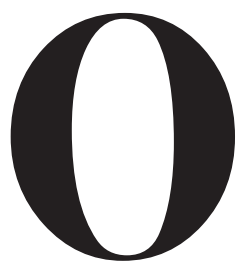

presente artigo centrar-se-á em uma figura muito polêmica, cujos escritos e ideias sobre arte moderna foram amplamente divulgados na América do Sul, a tal ponto que ela ajudou a conceber a coleção do primeiro museu de arte moderna no subcontinente, o Museu de Arte Moderna de São Paulo (MAM), a crítica de arte italiana Margherita Sarfatti. Trataremos das relações da crítica italiana, Margherita Sarfatti (1880-1961) com o meio artístico brasileiro $^{2}$. Com exceção do autorretrato de Amedeo Modigliani, essas 71 pinturas não pareciam ter conexão nenhuma com a história que se contava sobre o antigo MAM, e sobre a arte moderna no Brasil. A historiografia da arte no Brasil, havia excluído essas obras e ignorado sua importância, bem como a desses artistas na história da arte moderna em geral, julgando-as obras de mau gosto, adquiridas sem qualquer critério, de acordo com a vontade do fundador e presidente do antigo MAM, Francisco Matarazzo Sobrinho, ou Ciccillo Matarazzo, nascido em uma rica família de imigrantes italianos no Brasil. ${ }^{3}$ Até recentemente acreditava-se que essas pinturas haviam sido adquiridas de acordo com seu gosto como colecionador privado, tendo sido deixadas para o antigo MAM como parte da construção de sua memória como figura pública.

Meu objetivo é demonstrar como esse conjunto de obras foi escolhido dentro do contexto específico de reabilitação da arte moderna italiana na arena internacional após a queda do regime fascista na Itália. Uma série de mostras de arte moderna italiana itinerou por diversas capitais da América do Sul entre 1946 e 1947, nas quais a ideia de Novecento Italiano, termo cunhado por Margherita Sarfatti, era utilizado para promover as obras exibidas. Concomitantemente, uma importante mostra de arte moderna italiana, organizada pelo Museu de Arte Moderna de Nova York (MoMA), apresentava uma interpretação oposta a essa visão. No MoMA, a mostra evitou incluir obras que representavam a noção de Novecento Italiano, para dar ênfase aos grupos de vanguarda das primeiras décadas do século 20.

Propomos, assim, discutir as conexões entre Sarfatti e as Américas do Sul e do Norte, e o que se encontra por trás do termo Novecento Italiano, e sua relação com os escritos dela. Por fim serão analisadas as mostras italianas exibidas na América do Sul para então compará-las com aquela organizada pelo MoMA, em 1949.

$$
* * *
$$

2 Para um estudo sobre essas obras, ver MAGALHÃES, 2016.

3 A biografia encomendada pelo próprio Matarazzo ao jornalista Fernando Azevedo de Almeida é utilizada como referência até hoje, já que não houve ainda qualquer iniciativa de um estudo aprofundado sobre o Ciccillo. (ALMEIDA, 1976). 
No período que se seguiu à liberação de Paris e o fim da II Guerra Mundial, a imprensa brasileira preocupava-se em expor testemunhos do conflito, dado que o Brasil entrara na Guerra em 1942, após o ataque a um navio comercial em águas brasileiras por um submarino alemão, próximo à Baía de Guanabara, no Rio de Janeiro. Ao mesmo tempo, o Brasil assistia ao crescimento dos meios de comunicação através da criação de jornais, revistas e periódicos em geral. A mais importante rede de jornais e revistas do período era os Diários Associados, cujo o dono, Assis Chateaubriand, fundaria outro importante museu e coleção no Brasil, o Museu de Arte de São Paulo (MASP), também com a ajuda de um imigrante italiano, que havia emigrado para o país no pós-guerra: o crítico de arte e galerista Pietro Maria Bardi. ${ }^{4}$

Foi para uma fotorreportagem sobre a guerra que o repórter estrela dos Diários Associados, o carioca Edmar Morel, foi enviado para a Argentina e Uruguai no início de fevereiro de 1945, para a produção de uma série de artigos que cobririam eventos extraordinários nesses países. Na Argentina, Morel entrevistou a crítica de arte italiana Margherita Sarfatti, que vivia como exilada em um luxuoso hotel em Buenos Aires desde 1939. A matéria intitulada "Porque amei Mussolini" foi publicada na revista A cigarra. Na chamada lê-se:

Edmar Morel, como enviado especial de A CIGARRA às Repúblicas da Argentina do Uruguai, inicia neste número uma série de reportagens sôbre (sic) o que êle (sic) viu nos dois grandes países sul-americanos. "Por que (sic) amei Mussolini" é o relato da vida agitada da escritora e poetisa fascista Margarita Sarfati (sic), a mulher que influiu de maneira poderosa na vida do Duce. (MOREL, 1945, p. 8)

O artigo mostra duas fotografias de Sarfatti. Na página dupla de abertura da matéria, à direita, acima, uma foto de Sarfatti [FIG. 1] sentada em sua escrivaninha no quarto de hotel de Buenos Aires, acompanhada da seguinte legenda: "A MARGARITA (sic) DE HOJE - A precursora da Gestapo na Itália vê seus dias correrem monótonos dentro do hotel em que reside, em Buenos Aires. Nada da pompa de outrora - o fascismo está morrendo no mundo." (MOREL, 1945, p. 8) Abaixo uma foto [FIG. 2] também dela reclinada em uma escrivaninha, com olhar melancólico, com a seguinte legenda: “A MARGARITA (sic) DE ONTEM - Considerada rica e talentosa, filha de um deão e espôsa (sic) de um advogado, uniu-se a Mussolini e fêz (sic) prevalecer para sua norma de vida as mesmas do fascismo". (MOREL, 1945, p. 8)

4 Sobre a chegada de Pietro Maria Bardi ao Brasil e seu envolvimento com a criação do MASP, veja-se POZZOLI, V. 1946! Porque Pietro Maria Bardi decide deixar a Itália e partir para o Brasil? In: MAGALHÃES, A. G; RUSCONI, P.; MIGLIACCIO, L. 2013, disponível em: http://www.mac.usp.br/mac/conteudo/academico/publicacoes/ anais/modernidade/pdfs/VIVIAN_PORT.pdf . Bardi foi também uma figura importante na promoção da arte moderna italiana no Brasil no segundo pós-guerra. 
Fig. 1 - Margherita Sarfatti escrevendo em seu apartamento de hotel em Buenos Aires. Foto publicada na matéria de Edmar Morel para a revista A Cigarra, fevereiro de 1945.

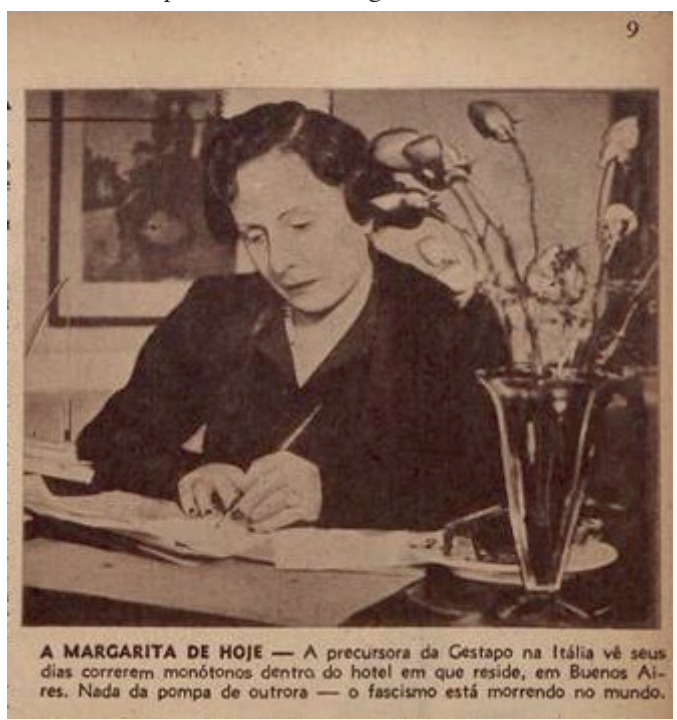

Fig 2 - Margherita Sarfatti em seu apartamento de hotel em Buenos Aires. Foto publicada na matéria de Edmar Morel para a revista A Cigarra, fevereiro de 1945.

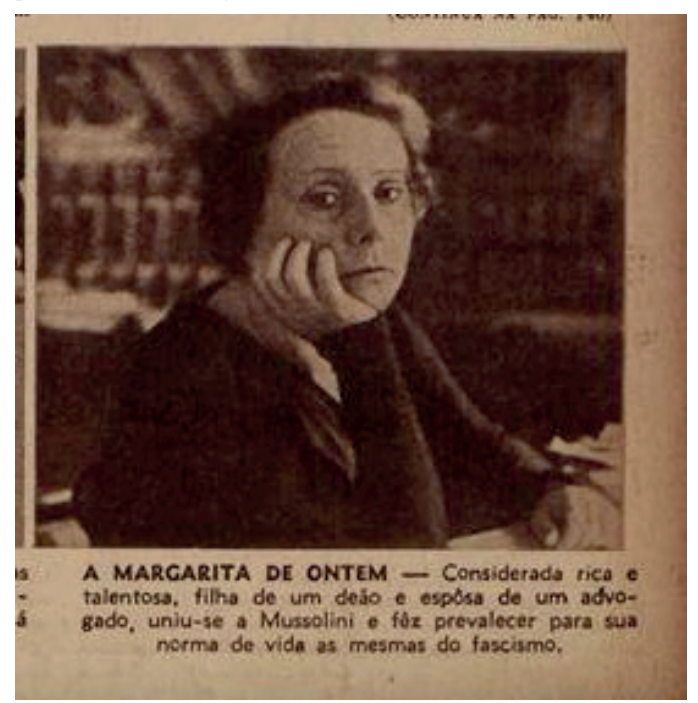


Edmar Morel fala das conexões de Sarfatti com a América do Sul, escrevendo sobre sua amizade com a elite brasileira, sua viagem à região em 1930, seu envolvimento com o grupo artístico do Novecento Italiano e seu papel, tanto como ideóloga fascista, quanto como crítica e colecionadora de arte. Entre os amigos brasileiros de Sarfatti, Morel cita o escritor e médico Aloysio de Castro, que havia sido presidente do chamado Instituto Ítalo-brasileiro de Alta Cultura, assim como da Sociedade "Amigos da Itália", ambos fundados no Rio de Janeiro, no início dos anos de 1930, momento no qual ele também era presidente da Academia Brasileira de Letras. ${ }^{5}$ Essas atividades fariam de Aloysio de Castro um dos intelectuais brasileiros a receber o grupo de intelectuais e políticos fascistas que vieram ao país em 1937 para uma viagem aos países da América do Sul, organizada pelo senador e ideólogo fascista Luigi Federzoni. A turnê foi ocasião para uma série de comícios e discursos, e uma forte promoção da arte e indústria italiana através da organização do pavilhão italiano da mostra de 50 Anos da Imigração no Estado de São Paulo.

A correspondência de Sarfatti com De Castro neste período é constante. ${ }^{6}$ De Castro a incentivou a se unir à viagem de Federzoni, o que acabou não acontecendo. Os dois continuaram, no entanto, se correspondendo, até o momento da chegada de Sarfatti ao Brasil, em 1939, na parada de sua viagem para estabelecer-se em Montevidéu. Na imprensa brasileira ela foi vista ao lado de De Castro ao desembarcar, em uma pequena nota publicada no Diário da Noite: "Escreveu a biographia (sic) de Mussolini” (DIÁRIO DA NOITE, 1939, p. 2) Nesse contexto é importante enfatizar sua relação com Aloysio de Castro, pois é dessa ligação que observamos ela aliar suas atividades políticas às artísticas, bem como afirmar sua crença perpétua nos valores do movimento artístico por ela encabeçado na década de 1920 e início de 1930 na Itália, os quais Sarfatti entendia como vitais para o que a Itália fascista deveria ser.

Margherita Grassini Sarfatti nasceu em Veneza, em uma rica família judaica em $1880 .^{7}$ Seu pai tornou-se um dos mais poderosos negociantes da cidade, onde fundou a empresa veneziana de vaporettos, no final do século XIX. Sarfatti cresceu em um momento importante para a afirmação da comunidade judaica na sociedade veneziana e italiana em geral, e foi da primeira geração de sua família a viver fora do Gueto de Veneza. Quando criança e adolescente, ela viveu em um elegante e tradicional palazzo no Canal Grande. Seus pais preferiram educá-la em casa, e por isso Sarfatti teve três professores particulares, sendo o último deles o criador da mais

$5 \quad$ Aloysio de Castro (1881-1959) foi presidente da Academia Brasileira de Letras entre 1930 e 1951. Sobre o Instituto de Altos Estudos Ítalo-Brasileiros, ver Decreto Lei n. 24.687 de 12 de julho de 1934. Disponível em: http:// www.planalto.gov.br/ccivil_03/decreto/1930-1949/D24645.htm.

6 Veja-se correspondência entre Aloysio de Castro e Margherita Sarfatti, em especial a carta datada de 9 de outubro de 1936. Fundo Margherita Sarfatti, Archivio del ‘900, Museo di Arte Moderna e Contemporanea di Trento e Rovereto - MART.

$7 \quad$ Há algumas biografias importantes sobre Sarfatti, entre a Itália, a França, os Estados Unidos, e a Argentina. Veja-se, sobretudo, Sullivan B. CANNISTRARO, P. Il Duce's Other Woman. Nova York: William Morrow \& Company, 1993 e LIFFRAN, F. L'Égerie du Duce. Paris: Seuil, 2009. Sobre seu exílio sul-americano, veja-se GUTMAN, D. El amor judío de Mussolini: Margherita Sarfatti, del fascismo al exilio. Buenos Aires: Lumiere, 2006. Todas elas têm um tom jornalístico, e embora bem documentadas, dão grande enfoque à vida de Sarfatti como ideóloga fascista. O livro que trata de sua figura do ponto de vista da pesquisa histórica é o de D’URSO, S. Margherita Sarfatti: dal mito del Dux al mito americano. Venezia: Marsilio, 2003. Em 2015, a crítica de arte e jornalista Rachele Ferrario também lançou uma biografia de Sarfatti como crítica de arte. FERRARIO, R. Margherita Sarfatti: la regina dell'arte nell'Italia fascista. Milano: Mondadori, 2015. Mesmo assim, seu livro não apresenta propriamente material inédito sobre Sarfatti e toma largamente a biografia de Sullivan e Cannistraro como referência. Nenhuma dessas publicações preocupou-se em investigar suas relações com o Brasil. 
importante instituição veneziana para a promoção da arte moderna: Antonio Fradeletto, idealizador da Bienal de Veneza. Isso certamente direcionou os interesses de Sarfatti para as artes, em adição ao amor que sua mãe nutria por literatura, em especial a inglesa. Sarfatti seguiria o mesmo caminho, estudando inglês, francês e alemão, ainda criança, e mais tarde aprendendo a falar e escrever em espanhol.

Além das artes, Sarfatti também mostrava interesse pelas novas ondas políticas em seu país, e com 16 anos se autointitulava socialista e feminista. Seu casamento, ainda jovem, com o advogado judeu Cesare Sarfatti foi sua forma de escapar da proteção familiar e participar do círculo de intelectuais socialistas em Milão no início dos anos 1900. Ela encontrou então uma forma de colaborar com o jornal socialista Avanti!, publicando seus primeiros textos como crítica de arte.

A atmosfera milanesa era perfeita para seu envolvimento tanto na política quanto nas artes. Ela testemunhou o nascimento do movimento futurista, que apoiaria no início, tornando-se amiga íntima do artista Umberto Boccioni, entre outros. Em Milão, ela foi apresentada a Benito Mussolini, tornando-se sua amante e rompendo com os intelectuais socialistas, assim como ele o fez, para marchar a seu lado na ascensão do regime fascista no país.

Depois da Marcha sobre Roma de 1922, marco da nomeação de Mussolini como primeiro ministro do parlamento italiano, Sarfatti dedicou-se a um grande projeto, ligando arte, feminismo e política. Seu primeiro passo foi dado em função do convite de uma editora inglesa para que ela preparasse uma biografia de Mussolini. The life of Benito Mussolini [A vida de Benito Mussolini] seria publicada em inglês em 1925, e teve sua primeira tradução para o italiano no ano seguinte, em 1926. Dux, como seria intitulada, trazia em sua capa o famoso busto do ditador que o escultor simbolista italiano, Adolfo Wildt, exibira na comemoração de um ano da Marcha sobre Roma, em 1923. Wildt foi um dos artistas que Sarfatti promoveu no período, comissionando a criação de seu próprio busto em mármore em 1929, como um par do busto de Mussolini. Apesar de não fazer parte do grupo de pintores criado e fomentado por Sarfatti a partir de 1923, as referências do escultor à escultura romana antiga e seu estudo da tradição clássica se alinhavam com o que Sarfatti defendia como o Novecento.

O termo Novecento foi cunhado por ela inicialmente para designar um grupo de seis artistas cujas obras retomavam os valores fundamentais da tradição clássica, ao reinterpretar as obras dos mestres do Renascimento, em especial do Quattrocento. Dois desses artistas foram colaboradores de Sarfatti nas organizações das iniciativas do grupo, ambos saídos da experimentação futurista para tornarem-se os artistas mais importantes para a criação da imagem do Regime na década de 1930. O primeiro era o pintor Achille Funi, de Ferrara, que iniciou uma renovação de sua linguagem pictórica ao voltar-se aos artistas do Quattrocento da Escola de Ferrara, em especial Cosmè Tura. A coleção que seria mais tarde adquirida para o antigo MAM de São Paulo, traria para o acervo uma pintura deste exato momento [FIG. 3], de seu chamado Realismo Mágico, e que ajudou a construir a interpretação das setenta e uma pinturas adquiridas para o 
museu sob a noção de Novecento Italiano. ${ }^{8}$ O segundo pintor era Mario Sironi, que se tornaria praticamente o pintor oficial do regime na década de 1930, e coordenador de comissionamentos para os mais importantes murais para prédios públicos durante a era fascista. Embora o Brasil tenha em território pelo menos seis pinturas de Sironi, adquiridas para a coleção do antigo MAM, nenhuma delas é do período de sua pintura do Novecento, independentemente de suas referências claras à tradição clássica italiana. ${ }^{9}$ Além da aquisição dessas obras, Sironi também teve uma mostra individual no antigo MAM em 1949, primeiro ano de atividade do museu.

Fig 3 - Achille Funi, “A adivinha”, 1924, óleo sobre madeira, 45,7 x 45,8 cm, Coleção Francisco Matarazzo Sobrinho - Museu de Arte Contemporânea da Universidade de São Paulo (MAC USP). (C) Foto Rômulo Fialdini, 2012.

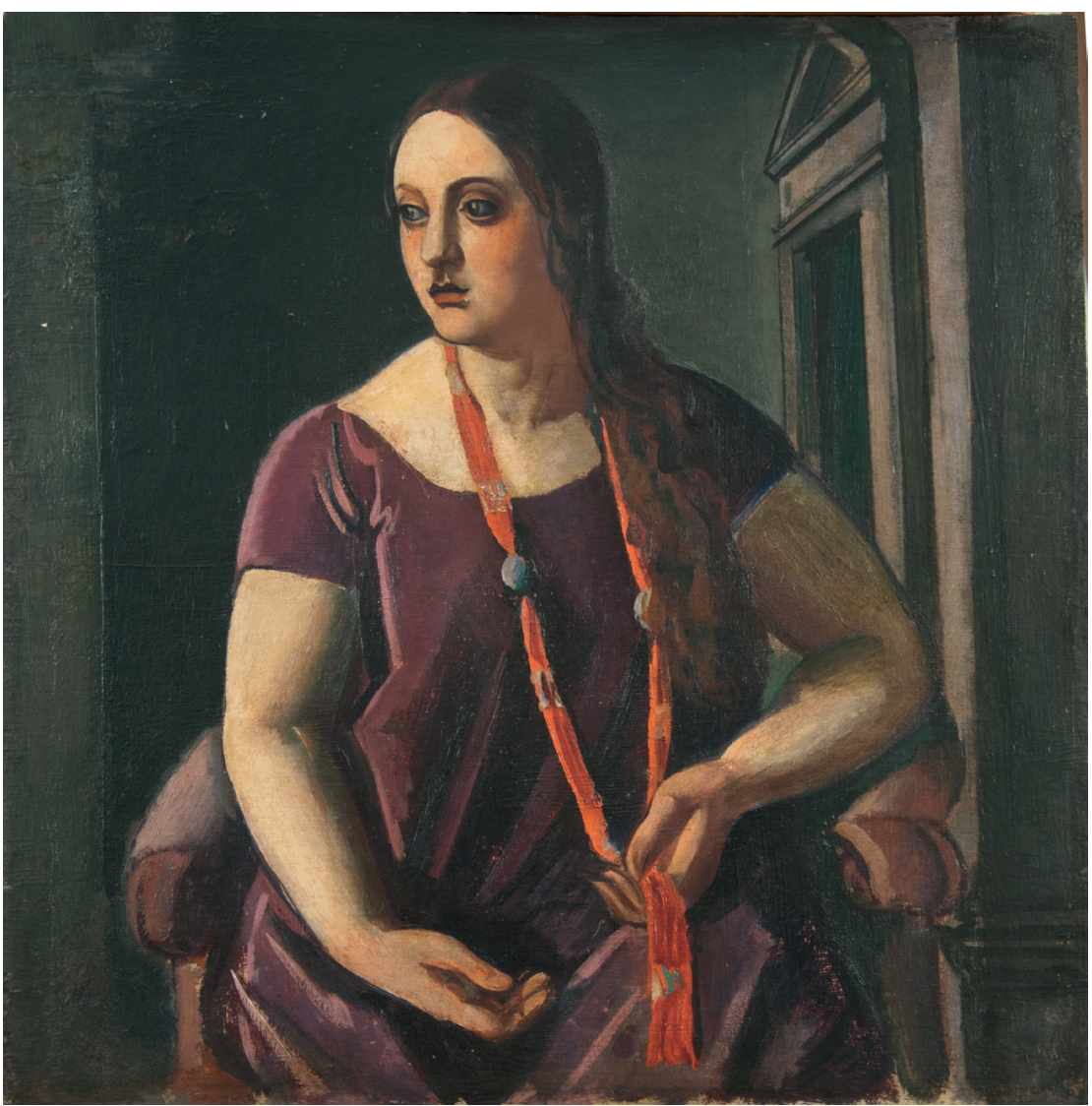

Trata-se de "A adivinha", 1924, óleo/tela, 45,7 x 45,8 cm, MAC USP. Para um estudo desta obra e sua relação com o Quattrocento ferrarês. (Cfr. MAGALHÃES, 2011, p. 349-358).

9 As obras de Sironi em questão, hoje pertencentes ao acervo do MAC USP, são objeto de estudo da pesquisa de mestrado de Andrea Ronqui, sob minha orientação. RONQUI, A. Mario Sironi nas chamadas Coleções Matarazzo do MAC USP. Revista Ars, vol. 15, no. 29, 2017, p. 101-120. 
Esse grupo inicial de seis artistas foi rapidamente reconfigurado. ${ }^{10} \mathrm{Na}$ primeira mostra do grupo em Milão em 1926, organizada por Sarfatti, o termo se expandiu para incorporar a nacionalidade dos artistas no nome do grupo, que a partir de então consistia de centenas de artistas de diversas origens, os quais, no entanto, na visão de Sarfatti, compartilhavam uma linguagem figurativa em comum, embasada na tradição clássica da arte. O problema da relação desse novo estilo e o fascismo marca o segundo momento de promoção do grupo. Mussolini foi convidado por Sarfatti a proferir o discurso da mostra inaugural do grupo, escrito por ela mesma, o qual falava explicitamente de uma arte oficial para o regime, na tentativa de transformar o Novecento Italiano na expressão da sociedade italiana sob o regime, a ideia de Nova Itália, e de modernidade, calcada em sua tradição clássica. ${ }^{11}$

A intensa campanha de promoção do Novecento Italiano de Sarfatti desdobrou-se em uma série de mostras no estrangeiro. Tais mostras chegaram à América do Sul, quando Sarfatti visitou o continente em 1930, pela primeira vez. Viajando como representante do regime fascista, ela organizou uma exposição do Novecento Italiano que circulou por Buenos Aires, Rosário e Montevidéu. ${ }^{12}$ Durante sua curta visita à América do Sul ela proferiu palestras sobre a pintura moderna em Buenos Aires, Rosário, e aparentemente promovia seu livro recém-publicado Storia della pittura moderna, no qual buscava interpretar a pintura moderna usando o paradigma da oposição entre síntese e análise. (SARFATTI, 1930) Dentro desse esquema, arte italiana correspondia às forças da arte de síntese, fundamentada na tradição clássica informada pela grande arte do Renascimento. A arte de análise, em contraste, seria típica da tradição dos países do norte da Europa, inclinados à abstração e emergindo em um período de crise. O livro tornou-se um grande sucesso na região, e extensos excertos foram publicados em jornais brasileiros. ${ }^{13}$

A partir de então Sarfatti tornou-se figura célebre na imprensa brasileira, onde se podia ler a respeito de suas viagens, da forma como se vestia, livros que publicava, prêmios que recebia. Foi o caso, por exemplo, de quando ela recebeu o Prêmio Galante de Literatura italiana, o qual lhe foi contemplado pelo livro L'America ricerca della felicità (SARFATTI, 1937) e no qual ela louvava as qualidades modernas dos Estados Unidos como sociedade e nação. O livro foi resultado de sua primeira e única visita ao país em 1934, quando foi convidada pela Society of the Women Feminist League [Sociedade da Liga de Mulheres Feministas] para proferir palestras a respeito da mulher moderna, que foi transmitida em rádio. O Brasil acompanhava essa viagem, como mostra um artigo a respeito da mulher norte-americana, de autoria de Sarfatti, publicado em O Jornal, em dezembro de 1935. (SARFATTI, 1935, p. 3) Intitulado A psicologia da mulher norte-americana, Sarfatti descrevia novos aspectos do comportamento dessa mulher, na qual ela percebia uma maior autonomia de movimento e espírito, ao ponto de serem mal-entendidas por homens, que viam certa liberalidade em suas maneiras e em suas atitudes em relação ao sexo oposto. O artigo aparece ilustrado por dois desenhos do artista e cenógrafo brasileiro Tomás Santa Rosa [FIG. 4].

10 Para uma história do Novecento Italiano, o estudo de BOSSAGLIA (1995) ainda é a referência mais importante. Veja-se também o estudo de BRAUN; ROSENTHAL (1989).

11 No fim, Mussolini alterou o texto escrito por Sarfatti e enfatizou uma autonomia da arte em relação ao Estado, o que a enfureceu. Sobre essa polêmica, veja-se PONTIGGIA, E. Il Novecento Italiano. Milano: Abscondita, 2003, que reúne as fontes sobre o episódio.

12 Cf. MOSTRA del Novecento Italiano. Buenos Aires: Amigos del Arte, setembro de 1930.

13 Veja-se, em particular, as matérias publicadas sobre o livro nos jornais O Paiz e Fanfulla. Cf. "Margherita Sarfatti fala-nos da missão que vem cumprir na América; Arte de hontem e de hoje - Expressões e valores - Arte italiana de 1900"(O Paiz, 1930, p. 5) e "La grande scrittrice e intenditrice d'arte, Margherita Sarfatti è giunta ieri a Rio" (Fanfulla, 1930, s.p.). Nos dois casos, um excerto idêntico do livro é publicado como citação de Sarfatti. 
Fig 4 - Tomás Santa Rosa, ilustração para artigo de Magherita Sarfatti, "Psicologia da mulher americana", O Jornal, 22 de dezembro de 1935.

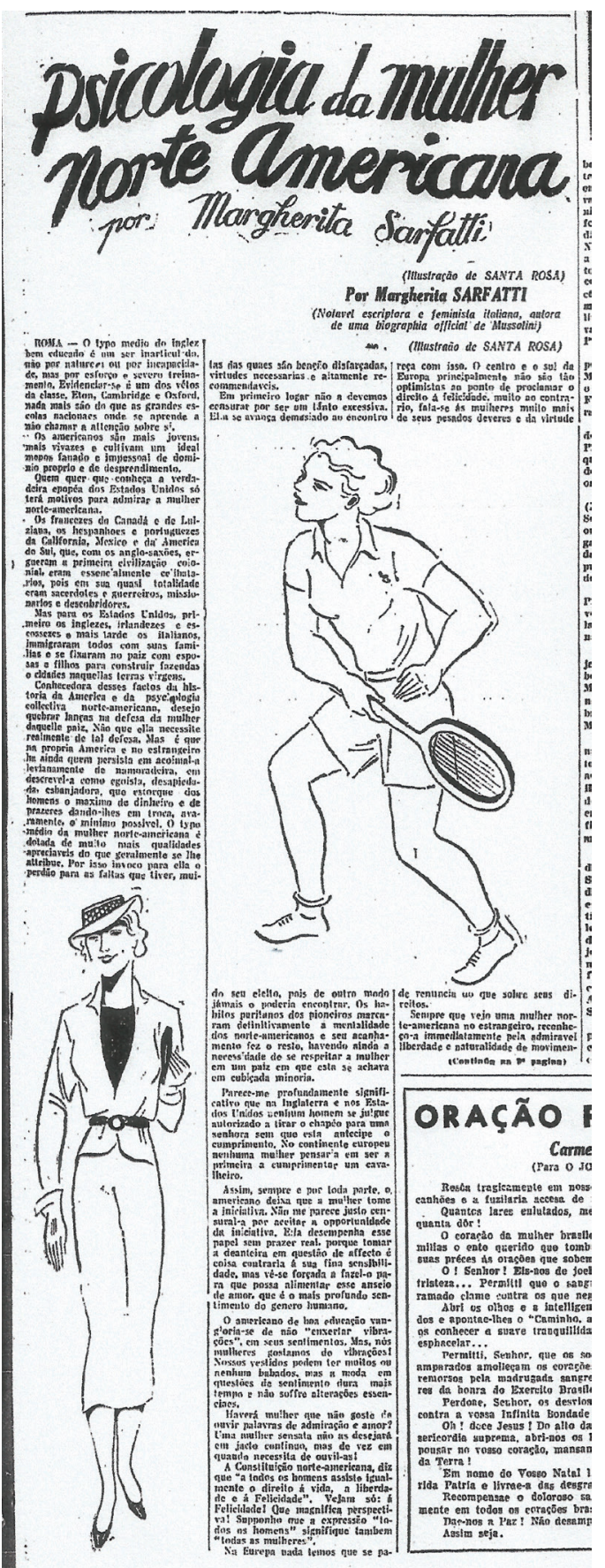


O conteúdo da argumentação de Sarfatti e as ilustrações de Santa Rosa parecem ter sido inspirados pelo livro La donna tipo tre, de Umberto Notari, publicado em Milão em 1929. ${ }^{14}$ Notari era amigo de Sarfatti, e se inspirou nela para teorizar sobre a existência de um terceiro tipo de mulher (que não era nem mãe, nem prostituída): financeiramente independente, autônoma em suas decisões, contribuindo para a construção da Itália como um país moderno.

A visita de Sarfatti aos Estados Unidos durou aproximadamente 6 meses, e resultou também em excursões pelo mundo da arte. Na edição do boletim do MoMA de maio de 1934, na seção "visitantes distintos", lê-se:

A Senhora Margherita Sarfatti é conhecida como biógrafa de Mussolini e sua colaboradora no jornal Il Popolo d'Italia. De importância ao menos equivalente é seu papel como defensora da vanguarda na pintura e arquitetura modernas. Ela tem sido patrona do Il Novecento - "século 20" - um grupo de artistas e escritores milaneses. (...) Entre seus livros está Storia della pittura moderna, o melhor livro-síntese a respeito da pintura moderna em italiano. ${ }^{15}$ (THE BULLETIN OF THE MUSEUM OF MODERN ART, 1934, p.4)

A nota aparece no mesmo momento em que o MoMA anuncia suas últimas aquisições para a coleção do museu, entre as quais, incluíam-se obras de artistas classicizantes italianos. Décadas depois, sua viagem e sua figura seriam imortalizadas em um filme norte-americano, não como promotora do Novecento, mas como promotora dos futuristas. No longa-metragem Cradle Will Rock [O Poder vai dançar], dirigido por Tim Robbins em 1999, a atriz Susan Sarandon faz o papel de Sarfatti. ${ }^{16}$ Duas cenas em especial se destacam nesse sentido: na primeira ela faz uma visita a seu amigo e artista mexicano Diego Rivera enquanto ele pinta o mural para o Rockefeller Center; na segunda ela é recebida pelo jovem Nelson Rockefeller, que havia acabado de adquirir por intermédio dela uma pintura futurista. Ela é representada no filme não apenas como uma crítica de arte, mas também como uma marchand inescrupulosa. Em uma cena no final do longa-metragem Sarfatti deixa o Rockefeller Center com duas malas de dinheiro para voltar para casa...

Pesquisadores, tanto na Itália quanto nas Américas, que estudaram sua vida como ideóloga fascista talvez tenham sido levados a desconsiderar dois importantes detalhes de sua vida como crítica e promotora de arte. Primeiramente, acredita-se que Sarfatti caiu em desgraça no círculo de poder fascista já no início da década de 1930; e que a queda final tenha se dado com a publicação das Leis Raciais na Itália em 1938, que a levou ao exílio em 1939. ${ }^{17}$ Em segundo lugar, aquilo que Sarfatti realizou depois de se estabelecer em Buenos Aires, por algum motivo, não é levado em conta, e entendido apenas como parte de anedotas curiosas sobre sua vida pessoal. O que nossa pesquisa revela não é uma personagem isolada, mas pelo contrário, Sarfatti viveu

14 O livro, apresenta ilustrações do artista Enrico Sacchetti que parecem remeter à ilustração do New Yorker do período.

15 "Signora Margherita Sarfatti is well known as a biographer of Mussolini and as collaborator with Mussolini upon the newspaper Il Popolo d'Italia. At least of equal importance is her role as advocate of the advance-guard in modern painting and architecture. She has been the champion of Il Novecento - " $20^{\text {th }}$ century" - a group artists and writers in Milan. (...) Among her books is the Storia della pittura moderna, the best short book on modern painting in the Italian language."

16 Veja-se a ficha completa do filme no IMDB, disponível em: https://www.imdb.com/title/tt0150216/?ref_=fn_al_tt_1. O filme pode ser assistido integralmente no Youtube (https://www.youtube.com/watch?v=rqPE0YYgwjI) . 17 Veja-se em especial as biografias de SULLIVAN ; CANNISTRARO (1993) e LIFFRAN, (2009). 
um momento muito produtivo de sua carreira como crítica de arte, cujas ideias a respeito da arte moderna circulavam, e eram aplicadas, para promover a arte moderna italiana através da designação de Novecento Italiano, tanto na Itália quanto na América do Sul.

Na década de 1930, na Itália, o uso do termo Novecento Italiano servia ao propósito de promoção da arte moderna italiana de forma geral, ao tentar apresentar diversas correntes através das lentes de seus traços latinos e mediterrâneos. Essa estratégia foi também importante na afirmação da identidade nacional italiana, tanto por recusar os "traços estrangeiros" da Escola de Paris, quanto por reafirmar a supremacia cultural italiana no contexto internacional. Mussolini, ao firmar sua aliança com a Alemanha de Hitler, transformou a promoção de mostras de arte moderna italiana nas capitais europeias em um projeto doméstico, capitaneado por Giuseppe Bottai, Ministro da Educação Nacional a partir de 1939, e colecionador de arte moderna italiana, através de uma política de incentivo à criação de coleções particulares de arte moderna italiana dentro do país. Esse projeto atingiu seu auge entre 1941 e 1942, quando uma série de mostras exibidas na galeria dos artistas do sindicato nacional (a Galleria d'Arte di Roma) apresentaram coleções particulares formadas nesse contexto. A mais ilustre destas era a coleção do editor veneziano, que logo se tornaria galerista, Carlo Cardazzo, de quem Matarazzo adquiriu sete pinturas para o antigo MAM de São Paulo 6 anos mais tarde..$^{18}$

Ao se falar de tais coleções, a noção de Novecento Italiano se mantinha, podendo, no entanto, simplesmente ser utilizada como sinônimo de arte italiana do século 20. Entretanto, o termo parecia comprovar que os artistas italianos eram descendentes da cultura latina mediterrânea, ou como os fascistas colocariam, de italianità (italianidade).$^{19}$ Nesse contexto, a história da arte italiana é entendida como tendo apenas uma corrente contínua, que se desenvolveu da antiguidade clássica até a era moderna. Sarfatti havia construído esse argumento já em 1927, quando publicou o artigo intitulado L'Arte e il fascismo [A arte e o fascismo], no qual escreve: "a arte, para nós italianos, é como um segundo nome da pátria”. (SARFATTI, 1928, p. 210)

De qualquer forma Sarfatti não parece ter chegado como fugitiva à América do Sul. Meses antes de sua chegada em 1939, uma curiosa foto de sua biblioteca em Roma foi publicada na seção “Ornamentação do lar” da Revista da Semana [FIG. 5].

18 Sobre a política de Bottai de promoção das coleções privadas de arte moderna italiana, veja-se por exemplo GIACON (2005, p. 51-68), sobre a exposição de coleções privadas italianas de Cortina d'Ampezzo, paralelamente às mostras na Galleria d'Arte di Roma.

19 Sobre essa questão, bem como a disseminação da latinidade, veja-se Catherine Fraixe, Lucia Piccioni \& Christoph Poupault (orgs.). Vers une Europe latine: acteurs et enjeux des échanges culturels entre la France et l'Italie fasciste. Bruxelas: P.I.E. Peter Lang; INHA, 2014. 
Fig 5 - A biblioteca pessoal de Margherita Sarfatti em seu apartamento em Roma, Foto publicada

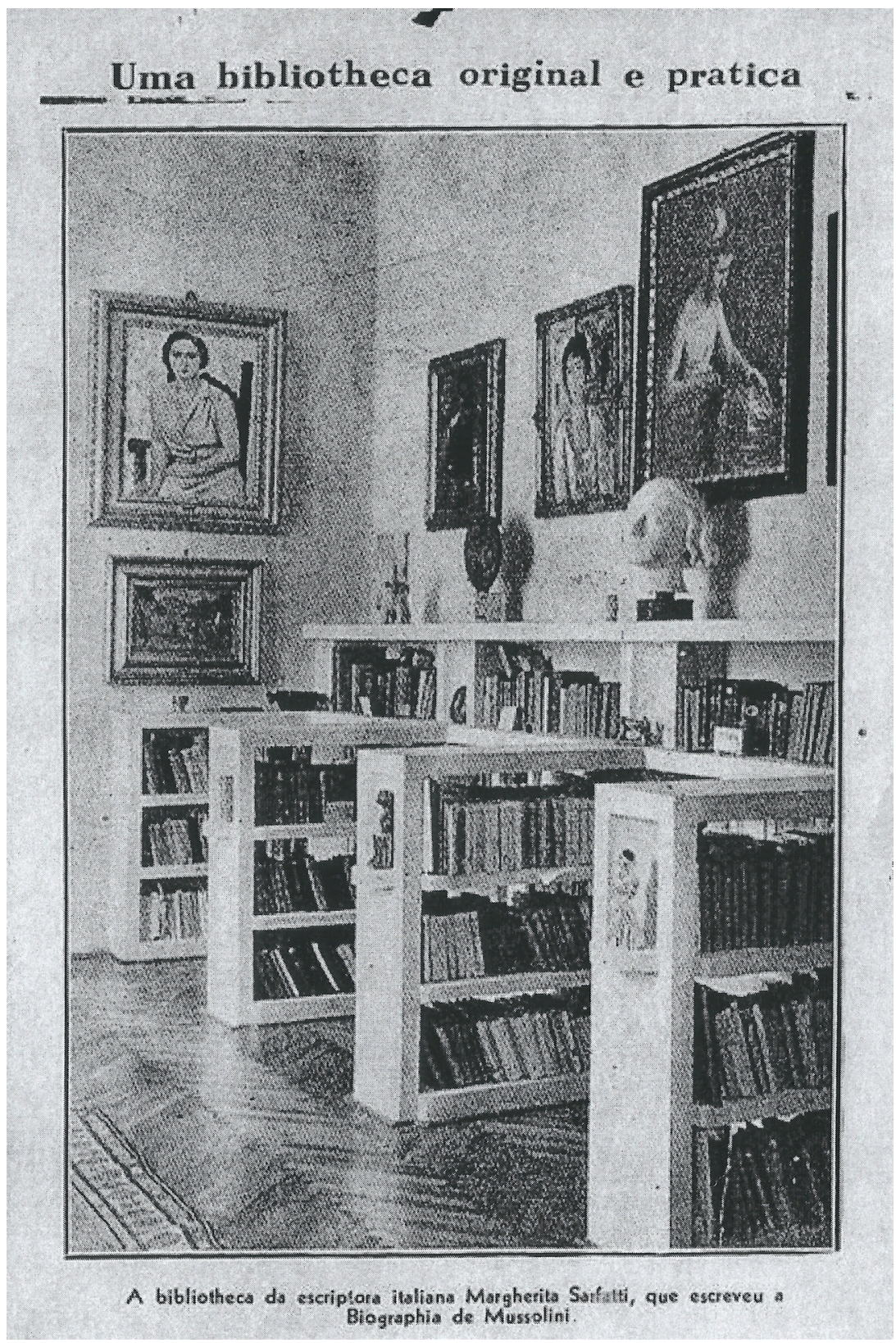


Na legenda lia-se: "Uma biblioteca original e prática”. (REVISTA DA SEMANA, 1939, p. 48) Sarfatti é mais uma vez lembrada como a biógrafa de Mussolini, e a foto permite reconhecer o busto que Adolfo Wildt fez dela na principal prateleira. A referência à biblioteca foi feita em um momento muito importante de promoção da arte moderna, tanto na Itália, quanto no Brasil. Na Itália, o fomento dado a coleções particulares era paralelo ao surgimento de edições especiais e publicações sobre artistas italianos do período, nas quais a ideia de bibliotecas especializadas era diretamente associada ao mundo da arte moderna na Itália, e as quais transformariam muitos galeristas milaneses (sendo Milão o centro comercial da arte no país) em editores e os levariam a estabelecer livrarias em seus espaços expositivos.$^{20}$ No caso do Brasil, e mais precisamente de São Paulo, esses anos foram de debate a respeito da revisão e renovação da biblioteca municipal da cidade, que foi reinaugurada em um prédio modernista em 1942. Pouco depois, o crítico Sérgio Milliet, seguindo os caminhos abertos por Mário de Andrade, criou a seção de arte moderna justamente nessa biblioteca, onde o primeiro comitê a conceber o MAM se reuniria em 1945. Milliet e Andrade foram dois críticos de arte que defendiam o grupo de pintores paulista, praticantes de uma pintura que consideravam possuir valores sociais e coletivos, que se reuniram em torno do pintor Paulo Rossi Osir, que os promoveu, na segunda metade da década de 1930. ${ }^{21}$ Esses “artistas-artesãos", como Mário de Andrade os chamaria, exibiram suas obras, entre 1937 e 1939, e seriam conhecidos como Grupo Santa Helena. Alguns deles, como o próprio Osir, de origem italiana, tiveram sua formação artística na Itália, onde testemunharam o debate do Novecento Italiano e do grupo de Sarfatti.

Mais importante, em termos da contribuição de Sarfatti como crítica de arte, é a conexão explícita entre seu novo livro sobre pintura moderna, publicado em Buenos Aires concomitantemente a sua ajuda a Matarazzo na aquisição de pinturas na Itália para o acervo do antigo MAM, e escritos do mesmo período de Milliet, e do crítico argentino Jorge Romero Brest. Este último não apenas foi o editor de Espejo de la pintura actual, publicado em 1947, mas também foi autor da primeira monografia a respeito da pintura moderna brasileira a aparecer na Argentina. ${ }^{22}$ Para tanto, Romero Brest estabeleceu intensa comunicação com Milliet, e tinha no crítico brasileiro o seu leitor de avaliação, por assim dizer. ${ }^{23}$ Em São Paulo, Milliet trabalhava em um livro que surgiu em 1942, e em 1949 seria tema de sua primeira palestra como membro brasileiro da AICA - Associação Internacional de Críticos da Arte, em Paris. Se por um lado seu Marginalidade da pintura moderna ${ }^{24}$ empresta o conceito de marginalidade da teoria econômica dos Estados Unidos da década de 1930 (em especial através da leitura de intelectuais da

20 A este respeito, veja-se doutorado inédito de Viviana Pozzoli, sob orientação do Prof. Paolo Rusconi: "Il sistema dell'editoria d'arte contemporanea nella Milano degli anni trenta", Dottorato in Scienze del Patrimonio Letterario, Artistico e Ambientale, Università degli Studi di Milano, Itália, defendida em dezembro de 2017.

21 Sobre o grupo Santa Helena, veja-se o estudo já clássico de ZANINI 1991; e mais recentemente, FREITAS, In: LODO, G. HARGRAVE, I. et al., 2012, p. 366-377. Disponível em: https://www.ifch.unicamp.br/eha/atas/2011/ ATAS.pdf.

22 Margarita (sic) G. de Sarfatti. Espejo de la pintura actual. Buenos Aires: Argos (Col. Arte y los artistas), 1947; e Jorge Romero Brest. La pintura brasileña contemporánea. Buenos Aires: Editorial Poseidon, 1945. A casa editorial na qual Romero Brest publicou seu livro é a mesma que havia publicado um ano antes, duas monografias de Sarfatti sobre pintores venezianos do Renascimento. Cf. Margarita (sic) G. de Sarfatti. Giorgione, el pintor misterio. Buenos Aires: Editorial Poseidon, 1944 \& Tiziano o de la fe en la vida. Buenos Aires: Editorial Poseidon, 1944. Ainda sobre as relações entre Sarfatti e Romero Brest, veja-se ROSSI (2005, p. 51-69).

23 Veja-se Fundo Jorge Romero Brest, Biblioteca Julio Payró, Departamento de História da Arte, Universidad de Buenos Aires.

24 Sérgio Milliet. Marginalidade da pintura moderna. São Paulo: Coleção "Departamento de Cultura" XXVIII, 1942. 
Escola de Chicago), por um lado, e por outro, parece completamente familiarizado com a visão de Sarfatti a respeito da evolução em ciclos da história da arte ocidental, alternando análise e síntese, sendo este também correspondente à retomada dos princípios da tradição clássica para Milliet. Ele publicou, mais tarde, uma resenha do Espejo de la pintura actual na sua coluna no jornal O Estado de S. Paulo, obra que Sarfatti explicitamente entendia como uma versão atualizada de Storia della pittura moderna de $1930 .{ }^{25}$ Em 1947 ela ampliou o número de capítulos da primeira edição do livro, incorporando um capítulo novo dedicado a pintores brasileiros e um apêndice a respeito dos pintores modernos da região do Rio da Prata. No caso do capítulo sobre o Brasil, sua ênfase foi, obviamente, nos pintores paulistas do Grupo Santa Helena. Portanto, o livro foi praticamente escrito para "explicar" a coleção adquirida para o antigo MAM: as aquisições italianas iriam acrescentar àquelas feitas por Matarazzo destes pintores brasileiros.

A noção de Novecento Italiano como sinônimo de pintura moderna italiana era ainda utilizada nos anos do imediato pós-guerra na promoção da arte moderna italiana na América do Sul. No entanto, desde o início dos anos 1940 já havia uma retomada das práticas de vanguarda e daquelas do meio parisiense na emergência de novas correntes - como do Gruppo Corrente, entre outros - primeiramente apresentados sob a lente do Novecento Italiano por exposições de iniciativa diplomática italiana para restaurar suas ligações com os governos aqui, depois da queda do Fascismo. Entre 1946 e 1947 - os mesmos anos de formação da coleção do antigo MAM - uma série de mostras de arte moderna italiana viajaram pelas principais capitais da América do Sul. A primeira aconteceu em Santiago do Chile e Buenos Aires, e propunha uma visão renovada da arte moderna italiana, ao mesmo tempo que efetivamente buscava romper com o Novecento Italiano. ${ }^{26}$ Quando resenhada por Romero Brest em sua Galería Peuser em Buenos Aires, a mostra assumiu um tom diferente, pois Romero Brest questionou a ausência de alguns artistas ligado ao Novecento Italiano. ${ }^{27}$

Em 1947, duas outras mostras de arte moderna italiana na América do Sul ainda enfatizavam o Novecento Italiano. Outro galerista milanês e promotor do Novecento de Sarfatti, Vittorio Barbaroux, apresentou sua coleção particular na Galería Müller em Buenos Aires,$^{28}$ e o crítico e galerista Pietro Maria Bardi, que se estabelecia no Brasil e auxiliava na fundação do MASP nos mesmos anos, organizou uma mostra de arte moderna italiana no Ministério da Educação e Saúde no Rio de Janeiro.

No caso da mostra de Bardi no Rio, ele claramente buscava um diálogo entre as pinturas apresentadas e as aquisições feitas pelo antigo MAM, ao mesmo tempo que enfatizava a pintura moderna italiana de inspiração na tradição clássica. Em seu texto para o pequeno catálogo da mostra Bardi usaria o termo "neoclassicismo contemporâneo" 29 para designar as pinturas em exibição. É também sintomático que um dos mais importantes críticos de arte moderna brasilei-

25 Cf. Sérgio Milliet, “Abril, 15” In: Diários críticos (Vol. VI). São Paulo: Martins Fontes/Edusp, 1981, p. 75-77. Originalmente publicado em sua coluna n'O Estado de São Paulo, em 15 de abril de 1948.

26 Cf. Pietro Zuffi (org.). Arte contemporâneo italiano. Santiago de Chile: Talleres Zig-Zag, 1946. Esse volume é bilíngue, em castelhano e português, o que nos faz levantar a hipótese de que também teria vindo para o Brasil, ainda que não se tenha até agora encontrado qualquer outra referência a ela no ambiente brasileiro.

27 Jorge Romero Brest, "De Chirico, Carrà y la Pintura Italiana del Novecientos", Histonium, ano VIII, n. 87, agosto de 1946, p. 487-494.

28 Cf. Artistas italianos de hoy. Buenos Aires: Galería Müller, julho de 1947 (Colección Victor Manuel Barbaroux). Sobre Vittorio Barbaroux e sua importância na promoção do Novecento Italiano, veja-se Elena Pontiggia \& Nicoletta Colombo (orgs.). Cat. exp. Milano anni trenta, l'arte e la città. Milano: Mazzotta, 2004, p. 60-63 e 323-325. 29 Exposição de Pintura Italiana Moderna. Rio de Janeiro: Studio di Arte Palma, maio de 1947. 
ro, Mário Pedrosa, ao comentar a mostra organizada por Bardi, também falasse sobre a vertente classicizante na arte moderna italiana. Nas palavras de Pedrosa

O fascismo trancou a grande nação do convívio do mundo, e hoje, quando nos defrontamos com seus artistas mais representativos no domínio da pintura, sentimos a alegria de quem revê a terra natal, pura, radiosa e linda como a sonhávamos, depois de uma longa ausência. Agora, felizmente, é o contato direto que se restabelece entre a velha Loba latina e nós, bugres sulamericanos que falam latim. [grifo meu] (PEDROSA, 1947, p. 31) $)^{30}$

Ao considerar um contexto ainda mais amplo, de como a Itália fez suas reparações com o fim da era fascista no cenário político internacional, o continente americano se provava um campo de batalhas ideológicas e de agendas políticas. Ao mesmo tempo que sociedades recém-nascidas e associações para-diplomáticas promoviam uma série de mostras que circulavam na América do Sul no pós II Guerra Mundial, os norte-americanos preparavam uma grande exposição de arte italiana do século 20. Em 1946, o conselho administrativo do MoMA deu aos curadores James Thrall Soby e Alfred Barr a função de preparar uma grande mostra de arte moderna italiana. Alguns incidentes adiaram a primeira viagem deles à Itália, mas em 1948, há correspondência dos dois, endereçada ao presidente do MoMA, Nelson Rockefeller, e ao então diretor do museu, sobre a estadia na Itália durante o verão daquele ano, quando tiveram a oportunidade de visitar a primeira Bienal de Veneza e a primeira Quadrienal de Roma do pós-guerra. ${ }^{31}$ Os atrasos na viagem se deram pois o MoMA decidiu que seus próprios curadores é

30 Se considerada no conjunto de sua produção crítica, o elogio que Pedrosa faz a essa produção de caráter mais classicizante é muito excepcional. Conhecido como defensor ardente das vanguardas históricas e das vertentes construtivas das artes visuais, é no mínimo curioso que o crítico tenha se dedicado a resenhar a exposição de Bardi. Por outro lado, havia entre os artistas escolhidos por Bardi, assim como entre aqueles comprados por Matarazzo para o acervo do antigo MAM, alguém como o bolonhês Giorgio Morandi, a quem Pedrosa tinha em grande conta. Talvez por isso seu elogio. Se considerarmos também que Pedrosa conhecia bem a produção de Alberto Magnelli, bem como outros artistas italianos presentes na mostra e nas aquisições Matarazzo, sua apreciação faz sentido. Mais surpreendente é ele exaltar nesse conjunto justamente os aspectos que ligariam esses artistas à tradição clássica - sua referência à loba latina, isto é, à tradição romana.

31 Cf. J.T.S. [James Thrall Soby], "Report on the Exhibition of $20^{\text {th }}$ Century Italian Painting and Sculpture, for the Museum of Modern Art", 7 páginas, The Museum of Modern Art Archives, MoMA Exhibitions Collection, Folder 413.6. A parte final do relatório de Soby é dedicado às "implicações políticas da exposição". Fica clara a intenção dos curadores de se afastar de qualquer debate político. Soby escreve: "Our show was not planned for political reasons. Our choice of works in Italy, though not yet final, was made solely on the basis of esthetic quality. (...) We made clear from the beginning that the political convictions of the artists would not be a factor in our judgment of their work. (...) We found on arrival in Italy that the majority of the living artists were Communists." [Nossa exposição não foi planejada por razões políticas. Nossa escolha de obras na Itália, ainda que não seja final, foi pautada somente pela qualidade estética das obras. (...) Deixamos claro desde o começo que as convicções políticas dos artistas não seriam um fator em nossa avaliação de suas obras. (...) Ao chegarmos na Itália, descobrimos que a maioria dos artistas vivos é de comunistas." No caso do MoMA, alguns artistas de filiação comunista foram selecionados para a exposição. O mesmo aconteceu no caso da mostra de Bardi e das aquisições Matarazzo. Exemplar, nesse sentido, é a presença de um artista como Renato Guttuso, no período da guerra ligado ao Gruppo Corrente di Vita Giovanile. O grupo havia criado um espaço em Milão desde a segunda metade da década de 1930, realizando encontros culturais e atividades antifascistas. Em 1941, com apoio do mecenato do industrial e colecionador de arte moderna italiana Alberto della Ragione, cria-se ali a Galleria della Spiga e Corrente, na qual a obra de Renato Guttuso comprada por Matarazzo é adquirida. Veja-se Renato Guttuso, "Natureza-morta com lâmpada", 1940, óleo/tela, 60,7 x 48,5 cm, MAC USP. A obra possui uma etiqueta da coleção Alberto della Ragione. Nos anos 1950, com a consolidação do debate em torno da abstração em pintura, Gut- 
que deveriam propor uma seleção de artistas e obras, sendo que a decisão não deveria então ser deixada para instituições e pares italianos, o que, obviamente, resultou em uma leitura diferente da arte moderna italiana. Apesar de ser possível identificar algumas das figuras ativamente circulando na América do Sul por trás de alguns dos empréstimos para a mostra do MoMA, há uma rejeição explícita ao modernismo conservador, classicizante, expresso pelo Novecento Italiano - mesmo que presente nas aquisições do MoMA de 1934. Barr e Soby deram um peso maior para o futurismo histórico (aquele das primeiras décadas do século 20, imaculado por qualquer ligação ao fascismo) através da figura de Umberto Boccioni, e para a pintura metafísica histórica na figura de Giorgio de Chirico. O Novecento Italiano foi mencionado apenas como parte do panorama do período entre guerras, quando esta teria sido a "principal escola de meados da década de 1920", "deliberadamente reacionária", segundo os curadores. (SOBY; BARR, 1949, p. 27)

Independente do peso diferente dado ao Novecento Italiano, e da incorporação de novos aliados no território italiano, incluindo a centralização de todos os contatos em torno do recém-estabelecido colecionador Romeo Toninelli, a seleção do MoMA ainda assim passava por nomes ligados à noção de Novecento Italiano, tais como os de Cardazzo e Sarfatti, sem mencionar Benedetta Cappa Marinetti, que fez empréstimos e vendas para a mostra de importantes obras futuristas, algumas das quais foram incorporadas à coleção do MoMA. ${ }^{32}$ Viúva do líder do movimento futurista, e pintora futurista, Benedetta contribuiu com as principais obras históricas da mostra, argumentando para que os curadores exibissem os futuristas do Ventennio - o que eles obviamente se recusaram a fazer. A respeito de Sarfatti, independentemente de sua associação direta com o Novecento Italiano, ela emprestou uma pintura futurista de Luigi Russolo de sua coleção particular. No pano de fundo da mostra do MoMA sobre arte moderna italiana e das mostras menores que aconteceram na América do Sul na segunda metade da década de 1940 há mais semelhanças do que aparentes à primeira vista.

Os norte-americanos tentaram montar um sistema das artes patrocinado por investidores e associações privadas, buscando o apoio de recém-criadas sociedades para-diplomáticas (como no caso das iniciativas de Bardi no Brasil) e coleções privadas. Embora esse talvez tenha sido uma forma de escapar de uma propaganda governamental nacionalista explícita, ele revela muito da forma norte-americana de fazer negócios no mundo da arte, algo que os italianos, desde a era fascista, aprendiam em sua busca pela modernização do país, e os sul-americanos tinham sido ensinados em debates que permitiram a criação de instituições de arte moderna, como o antigo MAM de São Paulo.

A grande diferença entre norte e sul é a forma com que o MoMA e os norte-americanos ne-

tuso aderiu aos indicativos do PC Italiano, permanecendo um pintor figurativo, o que lhe rendeu muitos problemas de inserção no meio artístico no período. De qualquer forma, e mesmo nos Estados Unidos, ele ainda encontrou apoio no mesmo James Thrall Soby para realizar uma exposição individual na ACA Gallery, em Nova York em abril de 1958. Cf. Cat. exp. Guttuso. Nova York: ACA Gallery/Heller Gallery, abril de 1958. Por fim, observe-se que a exposição de arte italiana do MoMA teria tido suas tratativas iniciadas ainda durante a II Guerra. Cf. Raffaelle Bedarida, "Export / Import: The Promotion of Contemporary Italian Art in the United States, 1935-1969", tese de doutorado sob orientação de Emily Braun, apresentada à Faculdade de História da Arte da City University of New York, em 2016, em especial o capítulo 2 .

32 Este é o momento no qual o MoMA adquire da viúva de Marinetti os bronzes de "Formas únicas da continuidade no espaço" (1913/1934) e "Desenvolvimento de uma garrafa no espaço" (1912/1934?). Veja-se correspondência entre Benedetta Cappa Marinetti e Alfred Barr no Fundo Benedetta Cappa Marinetti, Box 8, Special Collections, Getty Research Institute, Los Angeles. 
gociavam com os italianos. No caso da América do Sul parece não ter havido questionamento sobre as escolhas feitas pelos críticos e colecionadores de arte italianos, enquanto os mediadores nos Estados Unidos tomaram para si a tarefa de construir uma visão própria sobre o que a arte moderna italiana deveria ser, o que se transformou em uma tensão entre os curadores norte-americanos e o meio artístico italiano, cujos representantes não aceitavam as escolhas feitas pelos norte-americanos - questionados pelos italianos sobre sua expertise em fazê-lo. ${ }^{33}$

No entanto, em ambos os casos, o objetivo principal era financiar a arte italiana em novos mercados do continente americano, tanto do norte quanto do sul, e resultaram em importantes aquisições para ambos. A formação da coleção do antigo MAM de São Paulo tem de ser vista nessa perspectiva, na qual um lote inteiro de pinturas italianas fora adquirido em uma campanha de 10 meses na Itália para fomentar esse mercado. No caso do MoMA e do sistema das artes dos Estados Unidos, a mostra Twentieth Century Italian Art não apenas resultou na aquisição de obras importantes para a coleção do museu (como os dois bronzes de Boccioni que hoje podem ser vistos em suas galerias), mas também na formação de um gosto e mercado para a arte italiana ao longo da década de $1950 .{ }^{34}$

Há aspectos que devem ser considerados nessa operação de re-emergência da arte moderna italiana no continente americano no pós II Guerra Mundial. Além de abrigar as três maiores comunidades italianas fora da Itália, cidades como Nova York, São Paulo e Buenos Aires eram, desde o final da segunda metade do século XIX, a primeira escolha de italianos e políticas de imigração americana, que no caso da América do Sul favorecia o crescimento do comércio e indústria, ajudando a modernizar esses países..$^{35}$ Em segundo lugar, é interessante notar como os representantes dos Estados Unidos lidavam com seus pares italianos e sul-americanos. $\mathrm{O}$ estímulo para abraçar meios privados de apoiar arte e cultura, de ler a arte moderna em uma esfera autônoma através da ênfase em práticas vanguardistas/abstratizantes, e a recusa de qualquer estrutura nacional ou governamental para não "manchar" o discurso, por assim dizer, é um paralelo perfeito do livre mercado liberal promovido pela política externa norte-americana no pós II Guerra Mundial, que deu espaço à era da Guerra Fria.

Finalmente, o que parecia contraditório na formação da coleção do antigo MAM de São Paulo - pois segue uma direção contrária ao discurso da vanguarda e da abstração - talvez seja explicado dentro deste contexto mais amplo, do soft-power norte-americano na promoção da arte moderna como um valor no mundo ocidental. A hegemonia norte-americana foi sentida tanto na América do Sul quanto na Itália a partir de então, mas o soft-power dos Estados Unidos iria adotar formas diferentes em cada território, isto é, uma hierarquia também existia

33 Veja-se o memorando interno de James Thrall Soby a Monroe Wheeler (diretor administrativo do MoMA), de 9 de fevereiro de 1949: "The basic objections in Italy to our Italian exhibition are: 1. The Summer date which they dislike and cannot be persuaded is a good season here. 2 . The fact that Toninelli is the head of our Committee and as such the one responsible for the Italian end of the show. 3. The fact that the choice of pictures has been made by Alfred and me and not by Italian critics. (...)" [grifo meu] [As principais objeções na Itália à nossa exposição italiana são: 1. A data no verão, a qual eles não gostam e não se persuadem que é um bom momento aqui. 2 . O fato que Toninelli é o coordenador do nosso comitê e responsável como tal, em território italiano, da mostra. 3. O fato de que a seleção de obras foi feita por Alfred e por mim e não pelos críticos italianos].The Museum of Modern Art Archives, MoMA Exhibitions Collection, Folder 413.3.

34 No caso dos Estados Unidos, isso se comprova através da exposição que o MoMA organizou uma década depois em Roma, na Galleria Nazionale d'Arte Moderna. (Cft. BUCARELI; SOY,1960). Várias obras expostas aqui tinham vindo para a exposição de 1949 e foram compradas por colecionadores norte-americanos. No caso das exposições em circulação na América do Sul, as obras também vieram para venda, muito embora seja bem mais difícil sabermos o que permaneceu por aqui em coleções privadas.

35 Nesse sentido veja-se os estudos comparativos de BERTONHA (2001, p. 146-157). 
entre a Itália (berço da cultura europeia como equivalente universal de valores humanísticos que deveriam ser preservados a qualquer custo) e a América do Sul, esta última crescendo na arena internacional, reconfigurando-se em um território independente modernizado, que teria um papel importante nos novos mercados que cresciam então - sendo a arte chave para essa estratégia. Por um curto período, os representantes italianos teriam alguma liberdade para promover arte moderna italiana, reencenando a estratégia de ligá-la à tradição clássica. Uma vez que a elite brasileira, na figura de Matarazzo, decidiu criar a Bienal de São Paulo, seguindo o modelo da Bienal de Veneza, esse cenário mudou rapidamente. A Bienal contaria com o apoio de seus pares norte-americanos, mas a ênfase para eles estava em uma linguagem de arte abstrata, algo que os brasileiros iriam lutar contra durante algum tempo - assim como o fizeram seus pares italianos no contexto das primeiras bienais de Veneza que se deram no imediato pós II Guerra Mundial. 


\section{Referências}

ALMEIDA, F. A. de. O franciscano Francisco. São Paulo: Pioneira, 1976.

BERTONHA, J. F. Fascism and Italian communities in Brazil and in the United States: a comparative approach Italian Americana, Providence, 19, 2, 2001, p. 146-157.

BOSSAGLIA, R. Il Novecento Italiano. Milano: Charta, 1995 [1ª ed. 1976].

BRAUN, E.; ROSENTHAL, N. Cat. exp. Italian Art in the Twentieth Century: Painting and Sculpture, 1900-1988. Londres: Prestel, 1989.

BREST, J. R. La pintura brasileña contemporánea. Buenos Aires: Editorial Poseidon, 1945.

. De Chirico, Carrà y la Pintura Italiana del Novecientos. Histonium, ano VIII, n. 87, agosto de 1946, p. 487-494.

COOPER, D; SOBY, J. T.: LONGHI, R. Guttuso: [catálogo] April 7 to April 28, 1958. ACA Gallery/

Heller Gallery New York. Trad. John. W. Miller. Genève: Editions Internationales, 1958.

NOVECENTO Italiano. [catálogo] Buenos Aires: Amigos del Arte, VIII, set, 1930.

EXPOSIÇÃO de Pintura Italiana Moderna. [catálogo] Rio de Janeiro: Studio di Arte Palma, maio 1947.

ARTISTAS italianos de hoy. [catálogo] Buenos Aires: Galería Müller, jul. 1947 (Colección Victor Manuel Barbaroux).

BUCCARELLI, P; SOBY, J. T. Arte italiana del XX secolo da collezioni americane. Galleria Nazionale d'Arte Moderna di Roma, 16 de julho a 18 de setembro de 1960. Milano: Silvana Editoriale d'Arte, 1960.

ESCREVEU a biographia de Mussolini. Diário da Noite. Rio de Janeiro, 29 set. 1939, p. 3.

DISTINGUISHED VISITORS. The Bulletin of the Museum of Modern Art, Vol. 1, No. 9, May, 1934, p. 4.

D’URSO, S. Margherita Sarfatti: dal mito del Dux al mito americano. Venezia: Marsilio, 2003.

FEDERZONI, L. Parole fasciste al Sud America. Bologna: N. Zanichelli, 1938.

FERRARIO, R. Margherita Sarfatti: la regina dell'arte nell'Italia fascista. Milano: Mondadori, 2015.

FRAIXE, C.; PICCIONI, L.; POUPAULT, C. (orgs.). Vers une Europe latine: acteurs et enjeux des échanges culturels entre la France et l'Italie fasciste. Bruxelas: P.I.E. Peter Lang; INHA, 2014.

FREITAS, P. M. S. Grupo Santa Helena e o universo industrial paulista (1930-1970) In: LODO, G.; HARGRAVE, I. et al. (orgs.). Atas do VII Encontro de História da Arte. Os caminhos da história da arte desde Giorgio Vasari: consolidação e desenvolvimento da disciplina. Campinas: IFCH/UNICAMP, 2012, p. 366-377.

GIACON, D. Cortina, 1941. Rivista L'Uomo Nero: Materiali per una storia delle arti della modernità, v. 3, n. II, set. 2005, p. 51-68.

GUTMAN, D. El amor judio de Mussolini: Margherita Sarfatti, del fascismo al exilio. Buenos Aires: Lumiere, 2006.

LA GRANDE scrittrice e intenditrice d'arte, Margherita Sarfatti è giunta ieri a Rio. Fanfulla. São Paulo, 21 ago, 1930, s.p.

LIFFRAN, F. L'Égerie du Duce. Paris: Seuil, 2009.

MAGALHÃES, A. G. Achille Funi nella Collezione del MAC USP. Rivista L'Uomo Nero: Materiali per una Storia delle Arti della Modernità. Milano. Università degli Studi di Milano. Mimesis, Nuova Serie, ano VIII, $\mathrm{n}^{\circ}$ 7-8, set. 2011, p. 349-358.

. Classicismo moderno. Margherita Sarfatti e a pintura italiana no acervo do MAC USP. São Paulo: Alameda Editorial, 2016. 
MILLIET, S. Marginalidade da pintura moderna. São Paulo: Coleção "Departamento de Cultura" XXVIII, 1942.

. Abril, 15 In: __. Diários críticos (Vol. VI). São Paulo: Martins Fontes/Edusp, 1981, p. 75-77. MOREL, E. Porque amei Mussolini. A cigarra, Rio de Janeiro, fevereiro de 1945, p. 8-9, p.140, p.154-155.

NOTARI, U. La donna tipo tre. Milano: Società Anonima Notari (Istituto Editoriale Italiano), 1929.

MARGHERITA SARFATTI fala-nos da missão que vem cumprir na América: arte de hontem e de hoje - Expressões e valores - Arte italiana de 1900. O Paiz. Rio de Janeiro, 22 ago. 1930, p.5.

PEDROSA, M. Os italianos - sobretudo os jovens. Correio da Manhã. Artes Plásticas. Rio de Janeiro, 17 de maio de 1947 , p. 31.

PONTIGGIA, E. Il Novecento Italiano. Milano: Abscondita, 2003.

PONTIGGIA, E.; COLOMBO, N. (orgs.). Cat. exp. Milano anni trenta, l'arte e la città. Milano: Mazzotta, 2004, p. 60-63 e p. 323-325.

POZZOLI, V. 1946! Porque Pietro Maria Bardi decide deixar a Itália e partir para o Brasil? In: MAGALHÃES, A. G; RUSCONI, P.; MIGLIACCIO, L. (orgs.). Modernidade Latina. Os italianos e os centros do modernismo latino-americano. São Paulo: MAC USP, 2013, s.p. (disponível em: http://www. mac.usp.br/mac/conteudo/academico/publicacoes/anais/modernidade/pdfs/VIVIAN_PO RT.pdf ).

RONQUI, A. A. Mario Sironi nas chamadas Coleções Matarazzo do MAC USP. Revista Ars, vol. 15, no. 29, 2017, p. 101-120.

ROSSI, M. C. Una pulseada por la abstracción: Romero Brest entre Margherita Sarfatti y Lionello Venturi In: GIUNTA, A; COSTA, L. M. (orgs.). Arte de pós-guerra: Jorge Romero Brest y la Revista Ver y Estimar. Buenos Aires: Paidós, 2005, p. 51-69.

SARFATTI, M. Espejo de la pintura actual. Buenos Aires: Argos (Col. Arte y los artistas), 1947. . Giorgione, el pintor misterio. Buenos Aires: Editorial Poseidon, 1944.

__ Tiziano o de la fe en la vida. Buenos Aires: Editorial Poseidon, 1944. . .L'America, ricerca della felicità. Milano-Verona: Mondadori, 1937. . Storia della pittura moderna. Roma: Cremonese, 1930. $1935,3^{\text {a }}$ Secção, p. 3.

Psicologia da mulher norte-americana. O Jornal. Rio de Janeiro domingo, $22 \mathrm{dez}$ . L'Arte e il Fascismo. In: POMBA, G. L. (org.) La civiltà fascista. Torino: Unione Tipografica Torinese, 1928, p. 210-219.

.The Life of Benito Mussolini. Londres: Thornton Butterworth, 1925.

SOBY, J. T.; BARR, A. (orgs.). Twentieth Century Italian Art. Nova York: The Museum of Modern Art, 1949.

SULLIVAN, B.; CANNISTRARO, P. Il Duce's Other Woman. Nova York: William Morrow \& Company, 1993.

UMA BIBLIOTHECA original e pratica . Revista da Semana, Seção Ornamentação do Lar. Rio de Janeiro, 11 fev. 1939, p. 48.

ZANINI, W. Arte no Brasil nas décadas de 1930-40. O Grupo Santa Helena. São Paulo: Edusp/ Nobel, 1991.

ZUFFI, P. (org.). Arte contemporaneo italiano. Santiago de Chile: Talleres Zig-Zag, 1946.

Recebido: 20/06/2018

Aprovado: 22/09/2018 